\title{
A reestruturação da indústria brasileira: uma análise locacional - 1990 a 2016
}

Ariana Cericatto da Silva ${ }^{1}$

\begin{abstract}
Resumo: O padrão de localização brasileiro é bastante heterogêneo, refletindo na distribuição e participação regional nas diversas atividades industriais. Este artigo teve como objetivo analisar a distribuição espacial das atividades industriaisdentre os estados brasileiros no período de 1990 e 2016 . Utilizou-se como método de análise regional o Coeficiente de Reestruturação (CR) e o Quociente Locacional (QL). Os resultados do QL mostraram que São Paulo continua sendo o estado que mais concentra emprego industrial, seguido por estados do Sul e do Sudeste, no entanto, as atividades industriais em que esses estados se especializaramdemonstram que as atividades industriais brasileiras continuam atreladas a atividades mais tradicionais.
\end{abstract}

Palavras-chave: Análise Regional, Atividades Industriais, Especialização Produtiva Industrial, Estados Brasileiros, Mudança Estrutural.

Classificação JEL: L69; R12.

The restructuring of the brazilian industry: a locational analysis - 1990 to 2016

\begin{abstract}
The pattern of Brazilian location is quite heterogeneous, reflecting the regional distribution and participation in the various industrial activities. This article aimed to analyze the spatial distribution of industrial activities among the Brazilian states in the period of 1990 and 2016. We used as a regional analysis method the Restructuring Coefficient and the Locational Quotient. The QL results showed that São Paulo continues to be the state that most concentrates industrial employment, followed by southern and southeastern states, however the industrial activities that these states have specialized show that Brazilian industrial activities continue to be linked to more traditional activities.
\end{abstract}

Keywords: Regional Analysis. Industrial Activities. Industrial Productive Specialization. Brazilian states. Structural Change

\section{Introdução}

O Brasil passou por várias modificações na sua estrutura produtiva sob o efeito do acirramento concorrencial por parte das empresas, em virtude da maior abertura comercial do pós-1990, sendo as disparidades espaços-territoriais visíveis, sejam nos níveis regionais ou em relação às unidades federativas.

O período pós-abertura comercial impulsionou a alteração locacional de alguns setores, em especial da indústria, estimulada pela busca de novos espaços geográficos, pelos níveis mais baixos de remuneração salarial e pela oferta de incentivos fiscais por parte do Estado. Tais mudanças implicaram fortes impactos na produtividade física. No caso da indústria, esses impactos foram negativos, demonstrando queda na participação do Produto Interno Bruto (PIB), repercutindo no nível de emprego. Enquanto o Brasil atravessava essas grandes mudanças na economia, tais repercussões se estenderam para suas regiões e estados.

\footnotetext{
${ }^{1}$ Doutoranda em Economia pelo Programa de Pós-Graduação em Economia - PPGE da Universidade Federal de Uberlândia UFU. E-mail: ariana_cericatto@hotmail.com
} 
Há uma ampla literatura que investiga as relações entre indústria e território no Brasil no período da industrialização, contudo poucos estudos discutem as relações entre indústria e território no que se refere ao processo de reestruturação produtiva. É possível verificar que a maior parte da literatura regional sobre esse tema contempla estudos sobre desindustrialização. Assim, é latente a necessidade de avançar na discussão mais atualizada da reestruturação produtiva industrial, verificando como ela ocorre entre as regiões e os estados brasileiros.

Sendo assim, o presente estudo teve por objetivos identificar a distribuição do emprego formal nas atividades industriais dos estados brasileiros e verificar a ocorrência de mudanças na especialização produtiva, buscando captar alterações na estrutura da indústria brasileira. Nesse esforço de pesquisa, o artigo foi estruturado em mais quatro seções. Na segunda, é feita uma revisão sobre a configuração industrial brasileira. Na terceira, é apresentada a metodologia utilizada no trabalho, e na quarta, os principais resultados obtidos. Por fim, na última seção são apresentadas as considerações do trabalho.

\section{A abertura comercial e a indústria brasileira}

O período entre as décadas de 1930 e 1950 ficou conhecido como "industrialização restringida", porque a capacidade de investimento e crescimento da economia era limitada, e a indústria, ainda incipiente. De meados da década de 1950 até a década de 1980, se deu a "industrialização pesada", o parque industrial foi ampliado, constituindo-se a indústria de bens de capital e bens de consumo duráveis (COMIN, 2009).

Nos anos 1980, ocorreram várias mudanças tecnológicas no mundo, entre elas, a informática, a microeletrônica, a robótica e as telecomunicações. Internamente, a indústria brasileira passou por um período de intensos desequilíbrios no ambiente macroeconômico e institucional, que resultaram no esgotamento do processo de substituição de importações. A crise fiscal e financeira reduziu a capacidade de atuação do Estado na economia, assim como a entrada das regras do Consenso de Washington afetaram a indústria nacional em diferentes aspectos. Devido à crise fiscal, o Estado, que era caracterizado por induzir o desenvolvimento econômico do país, perdeu a capacidade de suplantar os investimentos. Consequentemente, a indústria brasileira não foi capaz de acompanhar esse novo paradigma produtivo e, ao final desse período, tornou-se muito defasada em relação às inovações tecnológicas de processo e de produto. Assim, a década de 1990 é marcada pela ruptura da trajetória econômica do Brasil. Nesse período, a indústria brasileira passou por uma fase de forte abertura comercial e financeira que se opunha à visão dominante até o final dos anos 1980, transformando o padrão de intervenção governamental (DE ARAÚJO, 1999; FILGUEIRAS, 2012; SAMPAIO, 2017; BRANDÃO, 2019).

Nessa perspectiva, o ambiente macroeconômico da década de 1990 tinha como objetivo a estabilização dos preços, a diminuição da intervenção estatal, a desregulamentação econômica e as privatizações das empresas estatais. Com essas reformas, houve uma elevação significativa no coeficiente de importação brasileiro, o que possibilitou uma maior participação das importações no país. O resultado dessas medidas para o setor industrial foi negativo de 1994 até 1998, havendo uma queda da participação da indústria provocada pela abertura comercial e pelo regime de política macroeconômica (âncora cambial) adotado no contexto do Plano Real (FILGUEIRAS, 2012).

No período de 1999 a 2004, houve uma recuperação da participação da indústria, que coincide com a desvalorização do real e com a adoção de um novo regime de política macroeconômica, baseado no tripé metas de inflação, superávit fiscal primário e câmbio flutuante, no entanto, essa participação não retornou ao nível anterior ao Plano Real (FILGUEIRAS, 2012; SAMPAIO, 2017).

A política neoliberal de abertura e privatizações potencializou os efeitos da Terceira Revolução Industrial (automação, substituição de trabalho dos insumos tradicionais, informatização, concentração do capital), de modo que a abertura econômica trazia uma falsa idéia de aumento da competitividade e de eficiência das empresas. Assim, a realidade econômica no comércio externo é a de que os países desenvolvidos possuem em suas pautas de exportação um elevado grau de especialização em produtos de média-alta tecnologia, o que os torna competitivos, enquanto os países subdesenvolvidos são 
"especializados" em commodities primárias e/ou em produtos manufaturados de pequena complexidade tecnológica, com baixa qualidade e eficiência (CANO, 1998; COMIN, 2009).

O Brasil está inserido em um tipo de estrutura produtiva e de inserção econômica internacional e, apesar de ter modernizado setores industriais do ponto de vista tecnológico e de gestão e de ter conseguido manter os setores industriais relevantes, a pauta de exportação do país tem se reprimarizado aceleradamente. Isso passou a ocorrer a partir de 2003, quando a tendência à valorização do real retornou e consolidou-se e, principalmente, entre 2006 a 2010, quando o efeito China ${ }^{2}$ passou a se manifestar de forma mais forte na economia mundial. A crise mundial, a partir de 2008 , reforça uma tendência regressiva da indústria brasileira (CANO, 2008; FILGUEIRAS, 2012; SAMPAIO, 2017).

Essa tendência regressiva ressalta e estimula a importância das commodities agrícolas e minerais para a redução da vulnerabilidade externa da economia brasileira e dificulta a diversificação e a ampliação industrial. A participação da indústria no PIB tem caído ao longo das últimas quatro décadas. Em 1994, a taxa de participação era de $26,79 \%$, sendo que, em 1995, ocorreu uma queda significativa, passando para 18,62\%. Em 1999, com a mudança do regime cambial para o tipo flutuante, ocorreu uma recuperação em termos da participação industrial, atingindo 19,22\% em 2004. Em 2011, a taxa de participação da indústria no PIB foi de 16,23\%. Em termos setoriais, ocorreu um crescimento da participação da indústria extrativa em relação à de transformação. A participação da primeira em relação ao total mais que dobrou de 1996 a 2007. A participação da indústria no PIB, em 2007, era de $7,95 \%$, ano anterior à crise internacional (SAMPAIO, 2013).

Constatam-se sinais da crise internacional na economia brasileira ao se verificar que a partir de 2008 o PIB acumulou queda de mais de $4 \%$ entre o último trimestre de 2008 e o primeiro semestre de 2009. O setor industrial foi o que mais contribuiu para a queda do PIB, com uma redução de $11,6 \%$, já o setor agropecuário registrou acréscimo de o,6\%, e o setor terciário cresceu 4,2\% (POCHMANN, 2009). Nesse cenário, sobressaíram as dificuldades da indústria de transformação brasileira em competir, tanto no mercado externo quanto no interno, enquanto as commodities agrícolas e minerais aumentaram sua participação no PIB e nas exportações. Os efeitos sinérgicos do boom exportador sobre o encadeamento interssetorial mostraram-se reduzidos, assim como tem sido percebido que o movimento da desconcentração regional passou a responder mais aos estímulos da demanda externa e menos à orientação interna do país de buscar a desconcentração como trajetória (MONTEIRO NETO; SILVA, 2018).

Um estudo realizado pelo Instituto de Pesquisa Econômica Aplicada (IPEA, 2012) corrobora essa situação ao considerar a relação entre valor adicionado e população ocupada. Constatou-se que o setor industrial ainda apresenta maior nível de produtividade em relação ao setor agrícola e de serviços, entretanto a produtividade na indústria de transformação apresentou queda. A indústria extrativa apresentou melhora na produtividade industrial puxada pelo setor de petróleo, o que reduziu os impactos na indústria como um todo. Este estudo sugere que vem ocorrendo uma convergência nos níveis de produtividade entre os setores agrícola, industrial e de serviços, contudo isso se deve à redução da produtividade no setor industrial e não à aceleração da produtividade dos demais setores.

Dessa forma, a abertura econômica teve influência sobre a produtividade, visto que reduziu o custo dos insumos e bens de capital, bem como incentivou a concorrência entre produtores nacionais e internacionais, de modo que esse choque competitivo fez com que os produtores nacionais tivessem que se modernizar para se adequar ao novo cenário, no entanto, esse choque não foi positivo para a maior parte da indústria brasileira. Além disso, o movimento de abertura econômica ocasionou uma reestruturação industrial do país, que teve, entre outros fatores, uma redução no tamanho médio das plantas industriais e uma realocação das indústrias nacionais.

\footnotetext{
${ }^{2}$ A partir dos anos 200o, com o ingresso e a participação da China nos fluxos comerciais e financeiros do mundo, a articulação China-EUA influenciou decisivamente o crescimento da economia mundial até quase o final de 20o8, com impacto positivo nos balanços de pagamentos dos países periféricos ao possibilitar o crescimento da demanda por recursos naturais e commodities agrícolas e minerais, com o aumento de preços e de quantidades (FILGUEIRAS, 2012).
} 
É importante salientar que esse processo evidencia alguns dilemas e desafios da inserção do Brasil em um mundo mais globalizado, especialmente destacando-se o fato de que as mudanças técnicas incidem sobre a indústria e os serviços, causando impacto sobre as estruturas ocupacionais e o emprego, e, portanto, traz intrinsecamente alterações na dimensão do espaço da localização econômica, o que pode reforçar os desequilíbrios regionais já existentes.

\subsection{A reestruturação da indústria brasileira}

Com base no debate consolidado na literatura acadêmica brasileira (DINIZ, 1995; DINIZ; CROCCO, 1996; PACHECO, 1998; CANO, 1998; 2008;SAMPAIO, 2013; 2017), o processo de desenvolvimento regional no Brasil resulta de profunda mudança estrutural na economia e na sociedade. Tanto a consolidação da industrialização e modernização do campo quanto a forte urbanização com elevada concentração da população em metrópoles contaram com atuação do Estado nacional para sua ocorrência, desde as reformas da Era Vargas (1930-1950) e o crescimento industrial e de integração viária promovido pelo governo do então presidente Juscelino Kubitschek (1955-1960) até chegar à atuação coordenada pelos governos militares na forma dos planos nacionais de desenvolvimento (PNDs I e II) nas décadas de 1960 e 1970 (MONTEIRO NETO; SILVA, 2018).

A indústria brasileira teve uma tendência de desconcentração a partir dos anos 1970, alterando a configuração regional do país, pois anteriormente a esse período havia uma forte concentração industrial na região Sudeste, em especial em São Paulo. O Sudeste detinha 65,7\% do setor industrial nacional em 1950 (participação relativa no PIB e no valor de transformação industrial VTI regional, em \%), ou seja, elevada fração; em $1970(65,5 \%)$ manteve sua posição, quando então passou a apresentar pequenas e sucessivas reduções: $62,4 \%$ em $1980 ; 58,8 \%$ em 1990; $58,3 \%$ em 2000; e 55,4\% em 2010.A economia paulista foi a mais afetada pelo processo de reestruturação produtiva por três motivos: i) por ter o maior parque industrial do país; ii) por concentrar maior parcela das indústrias de maior intensidade tecnológica, justamente aquelas mais afetadas pela abertura comercial e financeira; e iii) porque liderou o processo de integração do mercado nacional, sob sua hegemonia (DINIZ, 1995; SAMPAIO, 2017).

Após um século de concentração industrial no estado de São Paulo e de polarização na sua área metropolitana nas décadas de 1970 e 1980, esse processo foi invertido iniciando um movimento de reversão da polarização e de desconcentração industrial para várias regiões do país. Esse processo resultou de vários fatores, em especial de: i) deseconomias de aglomeração na área metropolitana de São Paulo e criação de economias de aglomeração em vários outros centros urbanos e regiões; ii) da ação do Estado em termos de investimento direto, incentivos fiscais e construção da infraestrutura; iii) da busca de recursos naturais traduzida pelo movimento das fronteiras agrícola e mineral, com reflexos na localização de um conjunto de atividades industriais; iv) da unificação do mercado, potencializada pelo desenvolvimento da infraestrutura de transportes e comunicações, com efeitos sobre a competição interindustrial e a localização (DINIZ, 1995; DINIZ; CROCCO, 1996).

De acordo com Pacheco (1998), com relação ao caso brasileiro, a existência de economias de aglomeração poderia ser uma justificativa para o perfil de concentração da indústria doméstica; em contrapartida, o surgimento de deseconomias seria o ponto central para explicitar a reversão da centralização produtiva, sempre que acompanhadas por novas economias de aglomeração em outros espaços econômicos. Dessa forma, haveria uma tendência da indústria em evitar os altos custos da metrópole, deslocando-se para espaços econômicos fora da área central, em que os custos locacionais são mais baixos.

Na década de 1980, ocorre a exaustão do modelo de crescimento, com intervenção estatal devido à crise fiscal e financeira do Estado,que passou a impedir a continuidade do ritmo do crescimento industrial corrente ao fragilizar suas bases de financiamento. Nesse momento, ocorreu uma profunda inflexão na trajetória do desenvolvimento nacional, com o predomínio, a partir de então, de um padrão de baixo crescimento econômico associado a dificuldades para a expansão da renda gerada no setor industrial. O longo processo de mudança estrutural conduzido pela indústria teria chegado ao fim, comprometendo o ritmo e o sentido da dinâmica produtiva nacional, assim como a capacidade de atuar 
sobre a correção das disparidades regionais (DINIZ; CROCCO, 1996; SAMPAIO, 2017; MONTEIRO NETO; SILVA, 2018).

Na década de 1990, a perda generalizada de dinamismo econômico e o alargamento dos desníveis socioeconômicos entre as regiões foram determinados pelo ambiente macroeconômico internacional e pela redução da atuação do Estado. Isso resultou em descompasso entre os investimentos públicos e privados ao longo dos anos de 1990. As mudanças na paisagem regional brasileira foram consequência, em grande medida, de involuções e desconstruções, ou seja, geradas mais pelos impactos regionalmente diferenciados da crise econômica e pelas opções conservadoras de políticas macroeconômicas do que por processos reestruturantes (DE ARAÚJO, 1999; BRANDÃO, 2019).

As regiões se comportaram de forma diversa aos processos de abertura comercial, aos determinantes microeconômicos da reorganização empresarial, à deterioração da infraestrutura econômica e à desestruturação do setor público nos três níveis de governo da federação.As heterogeneidades inter e intrarregionais, em particular as últimas, cresceram bastante. Ampliaram-se ilhas de produtividade e pólos de competitividade, de produção e de exportação de alguns produtos em alta, com vulnerável especialização regressiva, sobretudo em commodities (BRANDÃO, 2019).

Monteiro Neto e Silva (2018) destacam que a transformação produtiva em curso na economia brasileira nas últimas duas décadas (199-2015) combina a existência de perda relativa de produto industrial no total da economia nacional, com desconcentração territorial em maior direção a estados das regiões Sul e Centro-Oeste do país. Segundo os autores, caracteriza-se como forma de ajustamento da indústria à situação de crise estrutural e, no entanto, ocorre associada à significativa desconcentração regional. $\mathrm{O}$ processo de desconcentração regional da indústria que se iniciou na década de 1970 continuou a ocorrer em intensidade relevante no período 1995-2015. A direção da desconcentração é mais intensa para a região Sul do país e para as economias estaduais da região Centro-Oeste.

No que tange à região, Monteiro Neto e Silva (2018) perceberam que as especializações produtivas ficaram também muito aparentes. As regiões Centro-Oeste, Norte e Nordeste concentram um número maior de ramos de atividade intensivos em recursos naturais. As regiões Sul e Nordeste especializaramse de maneira mais notável em ramos de atividade intensivos em trabalho, e a região Sudeste concentrou-se nos ramos intensivos em escala, diferenciados e baseados em ciências. Segundo as conclusões dos autores, a tendência à diversificação industrial ficou obstaculizada pela resposta brasileira à força exercida pela demanda externa por commodities e pela fraqueza dos elementos internos em incentivar novas opções setoriais. Sendo assim, a mudança estrutural capitaneada pelo impulso das atividades especializadas em recursos naturais não tem se constituído em elemento de diversificação do parque industrial brasileiro, nem setorial nem regionalmente.

De forma geral, a reestruturação produtiva, a abertura comercial e o novo papel do Estado na economia tiveram implicações sobre a ordenação industrial brasileira. Houve uma continuidade dessas mudanças após a implantação do Plano Real, pela inserção de investimentos externos estimulados pela valorização cambial. O processo de reestruturação industrial causou uma desconcentração espacial do setor,principalmente pelas estratégias das empresas em deslocar as indústrias das áreas tradicionais para novos espaços potenciais. Em suma, os processos que ocorreram a partir da década de 1990 determinaram importantes transformações nas relações entre as regiões brasileiras, com a reconcentração espacial da riqueza e da renda no período entre 1985-2016 e sinais de aumento das desigualdades inter e intrarregionais.

\section{Procedimentos metodológicos}

Para a aplicação da metodologia, foi utilizada a divisão geográfica do Brasil em estados. Conforme a divisão do Instituto Brasileiro de Geografia e Estatística (IBGE), o país possui 26 estados mais o distrito federal. Para a análise das atividades produtivas entre os estados brasileiros, foram utilizadas as medidas de localização regional, quais sejam, o Coeficiente de Reestruturação (CR) e o Quociente Locacional (QL), que serão melhor detalhados no tópico 3.2. Para a realização dos cálculos das medidas de localização regional, utilizou-se a variável emprego formal. 
Optou-se por utilizar a variável emprego formal para a estimativa do CR e do QL, por entender-se que os setores mais dinâmicos empregam mais trabalhadores formalizados no decorrer do tempo, especialmente em períodos de crescimento econômico. Por outro lado, o emprego formal reflete um perfil de emprego com proteção da seguridade social e dos direitos trabalhistas. Por isso, a expansão e a criação de mais postos de trabalho formais reflete não só a dinâmica econômica, pois mais emprego formal significa não apenas mais renda estável proveniente de salários e, com isso, mais consumo, como também melhorias sociais, já que mais cidadãos serão protegidos pela seguridade social e previdenciária (ALVES, 2012; DE LIMA et al., 2006; DE LIMA et al., 2009).

Os dados do emprego formal por atividade produtiva industrial e por estado foram obtidos por intermédio da Relação Anual de Informações Sociais (Rais) do Ministério do Trabalho e do Emprego (MTE). Tais registros contêm dados do emprego formal, de forma que captam: i) o aspecto locacional das atividades por estados e, ii) a desagregação das atividades industriais em: indústria do produto mineral não metálico; indústria metalúrgica; indústria mecânica; indústria do material elétrico e de comunicações; indústria do material de transporte; indústria da madeira e do mobiliário; indústria do papel, papelão, editorial e gráfica; indústria da borracha, fumo, couros, peles e similares; indústria química de produtos farmacêuticos, veterinários, perfumaria; indústria têxtil do vestuário e artefatos de tecidos; indústria de calçados e indústria de produtos alimentícios, bebidas e álcool etílico.

Essa base de dados apresenta apenas informações das empresas formalmente registradas. Dessa forma, esta pesquisa não abrangerá informações do emprego informal. Essa questão se mostra relevante, uma vez que a informalidade está presente na economia brasileira. No entanto, pela dificuldade de mensuração do setor informal, optou-se por não abordar esse aspecto.

O período que se utilizou para as medidas de análise regional foram os anos de 1990 e 2016. A escolha desses anos se justifica pela disponibilidade de dados e por entender que esse período retrata a abertura comercial brasileira e possíveis mudanças na especialização produtiva e na distribuição do emprego formal.

\subsection{Indicadores de análise regional}

Os primeiros pesquisadores a aplicar e sistematizar os indicadores de análise regional no Brasil foram Lodder (1971) e Haddad (1989). Ambos são referências importantes da aplicação empírica desse instrumental ao caso brasileiro. Entretanto outros estudiosos regionais fazem referência a esse instrumental analítico, como Alves et al. (2006); Costa (2002);De Lima et al. (2006); Piffer (1997; 2009); Piacenti e De Lima (2012), entre outros.

Para a estimativa dos indicadores de análise regional, é necessária a construção da matriz de informações e a organização das informações em uma matriz que relaciona a distribuição setorialespacial da variável-base. Após a construção das matrizes, o cálculo de diferentes tipos de medidas permite "descrever padrões de comportamento dos setores produtivos no espaço econômico, assim como padrões diferenciais de estruturas produtivas entre as várias regiões" (HADDAD, 1989, p. 227).

\subsubsection{A matriz de informações}

As informações foram organizadas em uma matriz, na qual cada linha mostra a distribuição total do emprego formal de uma dada atividade industrial entre os diferentes estados brasileiros, e cada coluna mostra como o emprego formal de um dado estado se distribui entre as diferentes atividades industriais. Para a construção da matriz define-se:

$$
\begin{aligned}
& E_{i j}=\text { emprego formal na atividade industrial }{ }^{i} \text { do estado } j \\
& E_{. j}=\sum_{i} E_{i j}=\text { emprego formal em todas as atividades industriais do estado }{ }^{j} ;
\end{aligned}
$$


$E_{i .}=\sum_{j} E_{i j}=$ emprego formal na atividade industrial $^{i}$ de todos os estados;

$E . .=\sum_{i} \sum_{j} E_{i j}=$ emprego formal em todas as atividades industriais de todos os estados.

Assim, pode-se apresentar a matriz de informação da seguinte forma:

Figura 1: Matriz de informação

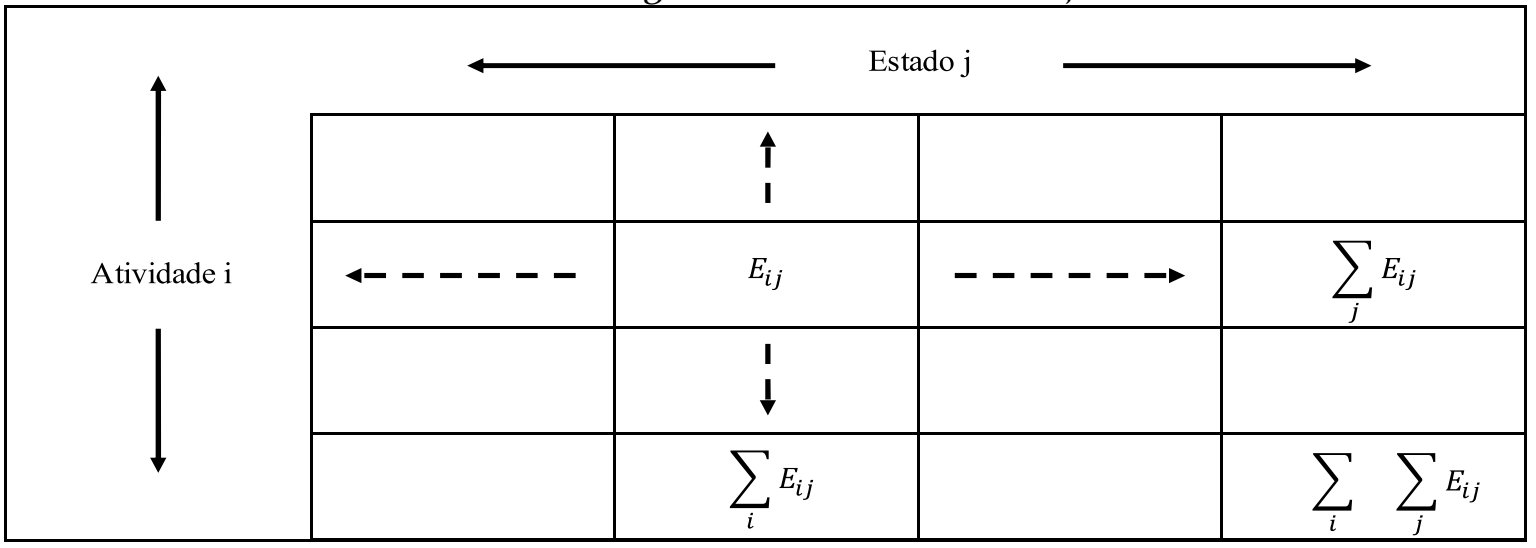

Fonte: Adaptada de Haddad (1989).

Com base nessa matriz, foram derivadas outras duas que mostram, em termos percentuais, a distribuição do emprego formal em cada estado por atividade e a distribuição do emprego formal de cada atividade entre os estados. Essas duas matrizes são demonstradas com as fórmulas:

$$
\begin{gathered}
i^{e} j=\frac{E_{i j}}{\sum_{i} E i j} \\
j^{e} i=\frac{E_{i j}}{\sum_{j} E_{i j}}
\end{gathered}
$$

sendo: $\sum_{i} i^{e} j=1,00 ; \sum_{j} j^{e} i=1,00 ; i^{e} .=\sum_{j} i^{e} j ;$ e $j^{e} .=\sum_{i} j^{e} i$

Elas fazem parte dos cálculos das medidas de localização, do coeficiente de reestruturação e do quociente locacional, que serão detalhados no tópico 3.2. 


\subsection{Medidas de localização}

As medidas de localização são medidas de natureza setorial e se preocupam com a localização das atividades entre os estados. O principal objetivo é identificar padrões de concentração ou de dispersão espacial da variável-base num dado período ou entre dois ou mais períodos.

\subsubsection{Coeficiente de Reestruturação}

O coeficiente de reestruturação (CR) do estado ${ }^{j}$ foi definido:

$t_{1} t_{0}$

$$
C R_{j}=\frac{\sum_{i}(|i e j-i e j|)}{2}
$$

O coeficiente de reestruturação relaciona a estrutura do emprego formal no estado $j$ entre dois períodos (1990 e 2016), a fim de avaliar o grau de mudança na especialização desse estado. Quando o coeficiente for igual a zero, não terá havido modificações na composição setorial do estado. Se, por outro lado, o coeficiente for igual a um, terá ocorrido uma reestruturação profunda na composição setorial do estado. Neste trabalho, optou-se por criar intervalos a partir dos resultados obtidos afim de melhor analisar as mudanças estruturais ocorridas no período de 1990 a 2016 e assim realizar o primeiro objetivo aqui definido, o de avaliar o grau de mudança na especialização produtiva dos estados brasileiros nas últimas décadas.

\subsubsection{Quociente Locacional}

O quociente locacional (QL) de determinada atividade industrial ${ }^{i}$ no estado ${ }^{j}$ foi definido:

$$
Q L_{i j}=\frac{E_{i j} / E_{i .}}{E_{. j} / E . .}
$$

O quociente locacional compara a participação percentual de um estado em uma atividade industrial particular, com a participação percentual do mesmo estado no total do emprego formal nos anos de 1990 e 2016. Se o valor do quociente locacional for maior do que um, isso significa que o estado em questão é, relativamente, mais importante no contexto nacional em termos da atividade do que em termos gerais de todas as atividades. Dessa forma, foi possível responder o segundo objetivo deste trabalho, o de identificar padrões de especialização produtiva industrial com base no emprego formal nas atividades industriais dos estados brasileiros, buscando captar quais tipos de atividades vêm se destacando ao longo do tempo e de mostrar as possíveis distorções estaduais e regionais presentes na estrutura da cadeia produtiva industrial brasileira.

\section{Resultados e discussões}

No contexto apresentado na segunda seção deste trabalho, o qual referiu-se às transformações passadas pela indústria brasileira nas últimas quatro décadas (1970-2016), verificou-se que os autores indicam uma tendência regressiva do setor industrial. Essa tendência agrava as distorções regionais devido a especializações produtivas regionais. Assim, buscou-se verificar a distribuição do emprego formal nas atividades produtivas industriais por estados brasileiros e mostrar as possíveis distorções regionais presentes na estrutura da cadeia produtiva industrial brasileira. 


\subsection{A reestruturação do emprego formal nos estados brasileiros}

Com a utilização do Coeficiente de Reestruturação (CR), buscou-se detectar modificações estruturais das atividades produtivas industriais nos estados brasileiros no período de 1990 a 2016. A classificação para os resultados do coeficiente de reestruturação foi desenvolvida pela autora de acordo com a metodologia do CR apresentada na sessão 3.2.1 e baseada nos trabalhos de Da Silva (2014), Santos e Da Silva (2017) e Da Silva e Duarte (2018). Por essa classificação, pode-se ter uma compreensão mais específica dos resultados obtidos. Dado que o coeficiente varia entre zero e um, criaram-se três intervalos buscando agrupar valores mais próximos de zero (não significativo), valores intermediários (pouco significativos) e valores mais próximos de um (muito significativos).

Na Figura 2,verifica-se que os estados que mais se reestruturaram no período de 1990 a 2016 foram Rondônia, Maranhão e Tocantins, da região Norte e Nordeste. Já Ceará, Rio Grande do Norte, Paraíba, Pernambuco, Alagoas, Bahia, Rio de Janeiro, Espírito Santo, Minas Gerais, Goiás, Mato Grosso do Sul, São Paulo, Rio Grande do Sul, Santa Catarina e Paraná foram os que menos se reestruturaram, ou seja, apresentaram mudanças não significativas no que se refere às modificações estruturais das atividades produtivas nos estados brasileiros. Isso pode indicar que esses estados passaram por mudanças estruturais em períodos anteriores aos analisados. Observa-se que os estados que menos se reestruturaram no período de análise formam uma espécie de corredor e estão localizados nas regiões Nordeste, Sudeste, Centro-Oeste e Sul do país.

Figura 2: Coeficiente de Reestruturação das atividades produtivas industriais, segundo os estados brasileiros, 1990 e 2016

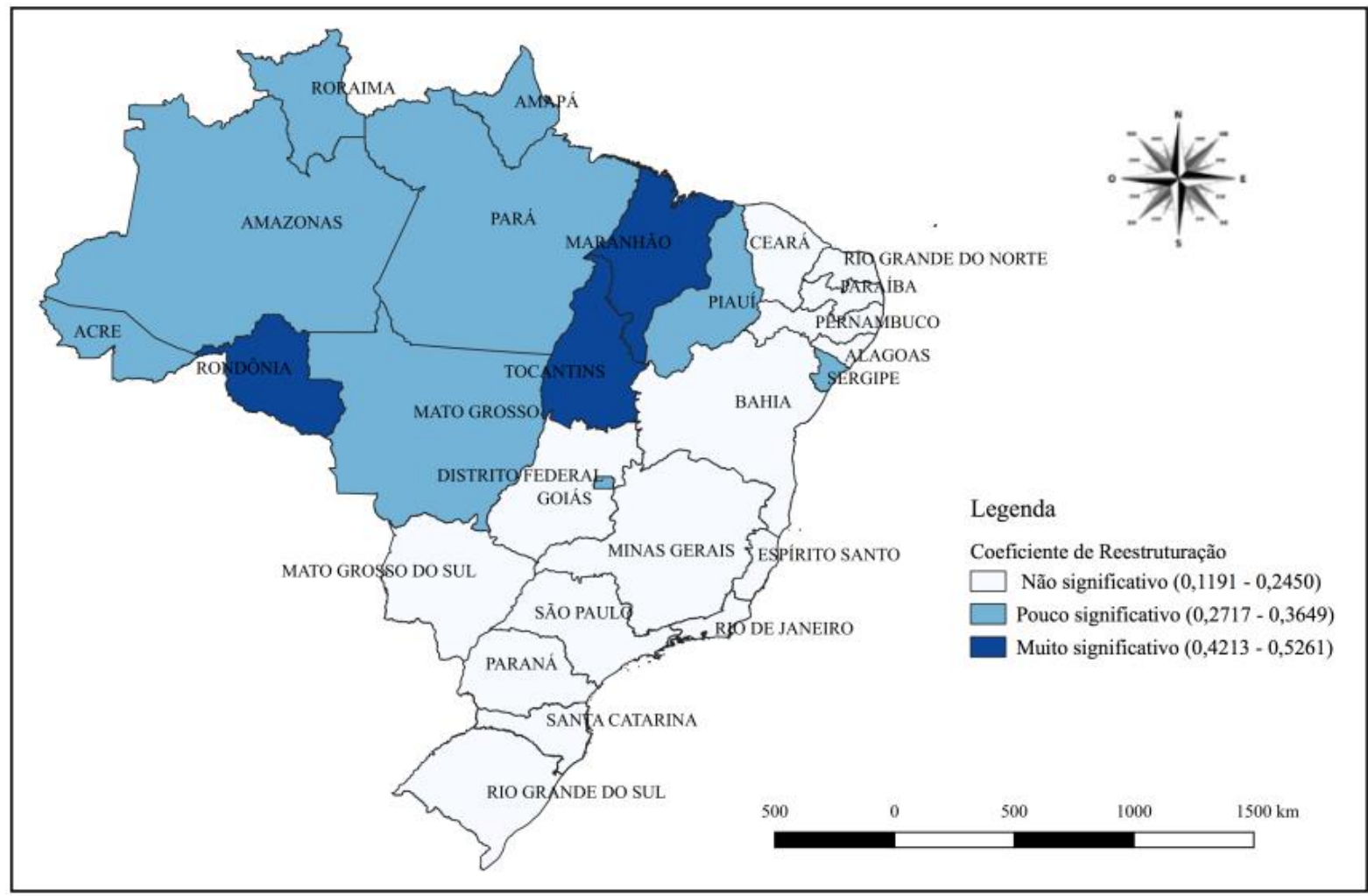

Fonte: Resultados da pesquisa com base nos dados da Rais (2018).

Os estados do Acre, de Roraima, do Amapá, do Pará, do Piauí, do Mato Grosso, do Amazonas, do Sergipe e o Distrito Federal apresentaram resultados do $C R$ no intervalo considerado pouco significativo, podendo-se inferir que esses estados permaneceram sem apresentar alterações significativas em suas estruturas produtivas no período analisado. 
O comportamento dos resultados do CR demonstra uma tendência de descentralização da produção industrial brasileira, assim como foi sinalizado e verificado em trabalhos como de De Araújo (1999), Cano (2008), Sampaio (2017), Monteiro Neto e Silva (2018) e Brandão (2019). Com as mudanças macroeconômicas ocorridas após 1990, a distribuição regional da produção se alterou de maneira a buscar outros espaços que não os tradicionais como São Paulo e Rio de Janeiro. No entanto, é importante salientar que essas mudanças não foram tão expressivas, de maneira que os estados tradicionalmente industriais mantiveram sua concentração nessa atividade, sendo possível verificar melhor através dos resultados do quociente locacional na sessão 4.2.

\subsection{Especializações do emprego formal nos estados brasileiros}

Ao se detectarem modificações estruturais nas atividades industriais nos estados brasileiros no período de 1990 a 2016, buscou-se identificar como se deram essas modificações com a utilização do Quociente Locacional (QL). Com esse indicador de análise regional, foi possível verificar o comportamento da especialização produtiva industrial entre os estados brasileiros. Como no caso dos estados que mais se reestruturaram, o estado do Tocantins deixou de ser especializado nas atividades da indústria metalúrgica, que em 1990 representava $32,58 \%$ do percentual do emprego formal entre as demais atividades industriais, e da indústria de madeira e mobiliário, que representava, em 1990, $26,54 \%$ do percentual do emprego formal. Sua especialização passou a se dar na atividade industrial de borracha, fumo, couros, peles e similares, conforme Quadro 1.

Já o estado de Rondônia, além das atividades em que era especializado em 1990, passou a ser especializado na atividade industrial de produtos alimentícios, bebidas e álcool etílico. Já o estado do Maranhão deixou de ser especializado na atividade industrial de madeira e do mobiliário, que em 1990 representava $43,21 \%$ do percentual do emprego formal do estado entre as atividades industriais, sendo este o maior percentual nesse ano, e passou a ser especializado nas atividades industriais de papel, papelão, editorial e gráfica; indústria de borracha, fumo, couros, peles e similares; indústria química de produtos farmacêuticos, veterinários, perfumaria e indústria de produtos alimentícios, bebidas e álcool etílico (Quadro 1).

Quadro 1: Perfil da reestruturação e das especializações dos estados brasileiros- 1990/2016

\begin{tabular}{|c|c|c|c|}
\hline Estados & $\begin{array}{c}\text { Especialização significativa }(\mathrm{QL}>1) \\
1990 \\
\end{array}$ & \begin{tabular}{|c|} 
Especialização significativa $(\mathrm{QL}>1)$ \\
2016 \\
\end{tabular} & CR 1990/2016 \\
\hline Tocantins & $\begin{array}{l}\text { Indústria de produtos minerais não } \\
\text { metálicos; Indústria metalúrgica; } \\
\text { Indústria da madeira e do mobiliário; } \\
\text { Indústria de produtos alimentícios, } \\
\text { bebidas e álcool etílico }\end{array}$ & $\begin{array}{l}\text { Indústria de produtos minerais não } \\
\text { metálicos; Ind. da borracha, fumo, } \\
\text { couros, peles, similares, ind. } \\
\text { diversas; Indústria de produtos } \\
\text { alimentícios, bebidas e álcool etílico }\end{array}$ & 0,526 \\
\hline Rondônia & $\begin{array}{l}\text { Indústria de produtos minerais não } \\
\text { metálicos; Indústria da madeira e do } \\
\text { mobiliário; }\end{array}$ & $\begin{array}{l}\text { Indústria de produtos minerais não } \\
\text { metálicos; Indústria da madeira e do } \\
\text { mobiliário; Indústria de produtos } \\
\text { alimentícios, bebidas e álcool etílico }\end{array}$ & 0,5203 \\
\hline Maranhão & $\begin{array}{l}\text { Indústria de produtos minerais não } \\
\text { metálicos; Indústria metalúrgica; } \\
\text { Indústria da madeira e do mobiliário; }\end{array}$ & $\begin{array}{l}\text { Indústria de produtos minerais não } \\
\text { metálicos; Indústria metalúrgica; } \\
\text { Indústria do papel, papelão, editorial } \\
\text { e gráfica; Ind. da borracha, fumo, } \\
\text { couros, peles, similares, ind. } \\
\text { diversas; Ind. química de produtos } \\
\text { farmacêuticos, veterinários, } \\
\text { perfumaria; Indústria de produtos } \\
\text { alimentícios, bebidas e álcool etílico }\end{array}$ & 0,4213 \\
\hline
\end{tabular}

Fonte: Resultados da pesquisa com base nos dados da Rais (2018).

Além disso, através dos resultados do QL verificou-se que a região Centro-Oeste apresentou especialização produtiva na atividade industrial de produtos alimentícios, bebidas e álcool etílico, ou seja, todos os estados nos dois anos analisados, 1990 e 2016, apresentaram QL maior que um. 
Analisando por estados, verificou-se que o estado do Mato Grosso do Sul se apresentou especializado somente nas atividades de indústria química de produtos farmacêuticos, veterinários e perfumaria; e na indústria de produtos alimentícios, bebidas e álcool etílico. O estado do Mato Grosso, nas atividades de indústria da madeira e do mobiliário e na indústria de produtos alimentícios, bebidas e álcool etílico. Goiás, somente na atividade industrial de produtos alimentícios, bebidas e álcool etílico; e o Distrito Federal, nas atividades industriais de produtos minerais não metálicos; na indústria de papel, papelão, editorial e gráfica; na indústria de borracha, fumo, couros, peles e similares; e na indústria de produtos alimentícios, bebidas e álcool etílico nos dois anos de análise.

A região Norte não se especializou, ou seja, nenhum dos estados, em nenhum dos anos analisados, apresentou QL maior que um nas atividades da indústria química de produtos farmacêuticos, veterinários e perfumaria; na indústria têxtil do vestuário e artefatos de tecidos; e na indústria de calçados.

O estado de Rondônia mostrou-se especializado, nos dois anos analisados, nas atividades da indústria de produtos minerais não metálicos e na indústria de madeira e mobiliário. Já o estado do Acre, também se especializou nas atividades industriais de produtos minerais não metálicos e na de madeira e mobiliário, e, além destas, na indústria de borracha, fumo, couros, peles, similares e na indústria de produtos alimentícios, bebidas e álcool etílico. O estado do Amazonas, na Indústria de material elétrico e de comunicações, na indústria de material de transporte e na indústria de borracha, fumo, couros, peles e similares. Os estados do Amapá e de Roraima, na indústria da madeira e do mobiliário; na indústria de papel, papelão, editorial e gráfica; e na indústria de produtos alimentícios, bebidas e álcool etílico nos anos analisados. O estado do Pará, nas atividades industriais de produtos minerais não metálicos, da madeira e do mobiliário e de produtos alimentícios, bebidas e álcool etílico. E o estado do Tocantins se especializou nos dois anos de análise, nas atividades industriais de produtos minerais não metálicos e produtos alimentícios, bebidas e álcool etílico.

Nenhum estado da região Nordeste apresentou especialização na indústria mecânica em nenhum dos anos analisados. Analisando por estado, o Maranhão somente se mostrou especializado na atividade industrial de produtos minerais não metálicos. Já o estado do Piauí, além desta, se mostrou especializado na indústria da madeira e do mobiliário; na indústria têxtil, do vestuário e de artefatos de tecidos; e na indústria de produtos alimentícios, bebidas e álcool etílico. Já o estado do Ceará, nas atividades da indústria de produtos minerais não metálicos e na indústria têxtil, do vestuário e de artefatos de tecidos. Os estados do Rio Grande do Norte, de Sergipe e da Paraíba apresentaram QL maior que um nas atividades industriais de produtos minerais não metálicos; na indústria têxtil, do vestuário e de artefatos de tecidos; e na de produtos alimentícios, bebidas e álcool etílico. $\mathrm{O}$ estado de Pernambuco também se mostrou especializado na indústria de produtos minerais não metálicos e na indústria de produtos alimentícios, bebidas e álcool etílico. Alagoas, somente na indústria de produtos alimentícios, bebidas e álcool etílico. O estado da Bahia, nas atividades industriais de produtos minerais não metálicos; na indústria de borracha fumo, couros, peles e similares; e na indústria química de produtos farmacêuticos, veterinários e perfumaria.

A região Sul não se mostrou especializada na indústria química de produtos farmacêuticos, veterinários e perfumaria, ou seja, nenhum estado em nenhum dos anos analisados apresentou QL maior que um para essa atividade. O estado do Paraná se mostrou especializado nas atividades da indústria da madeira e do mobiliário; na indústria de papel, papelão, editorial e gráfica; na indústria de produtos alimentícios, bebidas e álcool etílico. Santa Catarina, na indústria mecânica; na indústria da madeira e do mobiliário; na indústria têxtil do vestuário e de artefatos de tecidos. O estado do Rio Grande do Sul, nas atividades da indústria mecânica; da indústria de borracha, fumo, couros, peles e similares; e na indústria de calçados.

Verificou-se que a região Sudeste foi a região que apresentou maior especialização produtiva industrial, concentrando o maior percentual de emprego formal entre todos os estados. $\mathrm{O}$ maior responsável por isso foi o estado de São Paulo, que em 1990 concentrava 44,59\% de toda a mão de obra formal das atividades industriais brasileiras, e em 2016, 33,10\%. O estado de Minas Gerais concentrava $7,26 \%$ em 1990 e 10,24\% em 2016. O estado do Rio de Janeiro, em 1990, concentrava 8,11\% de todo o emprego formal industrial brasileiro, e em 2016, 5,36\%. Ele se mostrou especializado nas atividades da 
indústria do material de transporte; na indústria da madeira e do mobiliário; na indústria de papel, papelão, editorial e gráfica; na indústria de borracha, fumo, couros, peles e similares; na indústria química de produtos farmacêuticos, veterinários e perfumaria; e na indústria têxtil do vestuário e de artefatos de tecidos. São Paulo apresentou-se com especialização produtiva nas atividades da indústria metalúrgica; na indústria mecânica; na indústria do material elétrico e de comunicações; na indústria do material de transporte; na indústria da madeira e do mobiliário; na indústria de papel, papelão, editorial e gráfica; na indústria da borracha, fumo, couros, peles e similares; e na indústria química de produtos farmacêuticos, veterinários e perfumaria.

$\mathrm{O}$ estado de Minas Gerais mostrou-se especializado na indústria de produtos minerais não metálicos; na indústria metalúrgica e na indústria têxtil de vestuário e artefatos de tecido. O Espírito Santo possuía especialização produtiva na indústria de produtos minerais não metálicos; na indústria metalúrgica, assim como Minas Gerais, e na indústria da madeira e do mobiliário.

De acordo com Monteiro Neto e Silva (2018), verifica-se que os estados situados nas regiões Norte, Nordeste e Centro-Oeste especializaram-se mais em ramos de atividades intensivas em recursos naturais. Já as regiões Nordeste e Sul se concentraram mais em atividades de ramos intensivos em trabalho e a região Sudeste em escala baseada em ciências. Portanto, mesmo com a reestruturação produtiva industrial significativa de alguns estados das regiões Norte e Nordeste, o emprego formal continua concentrado na região Sudeste do país, com destaque para os estados de São Paulo, Minas Gerais e Rio de Janeiro. Além disso, é importante destacar que, no ano de 1990, o estado do Rio Grande do Sul apresentava o maior percentual de emprego formal por estados, $56,89 \%$ na indústria de calçados; e São Paulo, com 27,65\%, tinha o segundo maior percentual. Em 2016, o Rio Grande do Sul manteve o maior percentual de emprego formal nessa atividade, com 33,50\%, no entanto, o segundo maior percentual foi do estado do Ceará, com 18,74\%. Nas demais atividades industriais, o estado de São Paulo apresentou maior concentração do emprego formal nos dois anos analisados.

\section{Considerações Finais}

A intensificação do processo de globalização, no período pós-1990, ocasionou fortes transformações na economia mundial. No Brasil, tal processo impulsionou uma postura mais concorrencial da indústria nacional, principalmente como forma de esta se manter competitiva diante dos concorrentes externos. A partir da década de 1990, a economia brasileira passou a ser mais afetada pela reestruturação produtiva, que em conjunto com uma maior abertura da economia e com as novas políticas industriais implementadas no período gerou o estabelecimento de novas diretrizes para a economia.

Dessa forma, o presente estudo teve por objetivos identificar a distribuição do emprego formal nas atividades industriais dos estados brasileiros e verificar a ocorrência de mudanças na especialização produtiva, buscando captar alterações na estrutura da indústria brasileira.

No período de análise (1990-2016),verificou-se uma busca maior por novas localizações para as plantas industriais, principalmente para centros estratégicos que oferecessem uma estrutura de serviços e de vantagens equiparadas aos grandes centros, mas que não apresentassem elevados custos locacionais. Os resultados obtidos pelo coeficiente de reestruturação corroboram essa dinâmica ao demonstrar que os estados que mais se reestruturaram fazem parte das regiões Nordeste e Norte do Brasil que, na sua formação, não tiveram tradição para atividades industriais, mas que nas últimas décadas vêm se industrializando.

Em geral, verificou-se que o padrão de localização brasileiro é bastante heterogêneo, tendo reflexo na distribuição e na participação regional nas diversas atividades industriais, como no caso da região Sudeste, que se manteve como região altamente industrializada, mesmo com o processo de reestruturação pelo qual o Brasil passou pós-década de 1990. Os principais resultados do QL mostraram que São Paulo continua sendo o estado que mais concentra atividades industriais, seguido por estados como Minas Gerais, Rio de Janeiro, Paraná, Santa Catarina e Rio Grande do Sul. Esses resultados se assemelham às literaturas apresentadas na sessão dois, que trataram de períodos anteriores e que 
previam ou identificaram esse comportamento como consequência da conjuntura macroeconômica e das políticas adotadas nessas décadas.

Os resultados obtidos mostram que, no período de 1990 a 2016, as regiões brasileiras conheceram transformações limitadas em suas estruturas industriais. Quanto a esse aspecto, o desempenho industrial das regiões brasileiras e, consequentemente, de seus estados, pareceu seguir uma trajetória de aproximação à estrutura industrial do Brasil em sua totalidade. Trata-se, por conseguinte, da confirmação do caráter pouco dinâmico e menos complexo da indústria.

\section{Referências}

ALVES, L. R.; DE LIMA, J. F.; RIPPEL, R.; PIACENTI, C. A. O continuum, a localização do emprego e a configuração espacial do oeste do Paraná. Revista de História Econômica e Economia Regional Aplicada. vol. 1, n. 2. 2006.

ALVES, L. R. Indicadores de localização, especialização e estruturação regional. In.: PIACENTI, C. A.; DE LIMA, J. (Orgs.) Análise Regional: Metodologias e Indicadores. Curitiba, PR: Camões, 2012.

BRANDÃO, C. A. Mudanças produtivas e econômicas e reconfiguração territorial no Brasil no início do século XXI. Revista Brasileira de Estudos Urbanos e Regionais, São Paulo, v.21, n.2, p.258-279, 2019. DOI: https://doi.org/10.22296/2317-1529.2019v21n2p258

CANO, W. Desequilíbrios regionais e concentração industrial no Brasil, 1930 - 1995. 2. ed. Campinas, SP: UNICAMP. IE, 1998.

CANO, W. Desconcentração produtiva regional do Brasil, 1970-2005. São Paulo: Editora Unesp, 2008.

COMIN. A. A desindustrialização truncada: perspectivas do desenvolvimento econômico brasileiro. Tese de Doutorado IE/Unicamp, 2009.

COSTA, J. S. (Org.). Compêndio de economia regional. APDR. Coimbra: Gráfica de Coimbra Lda., Lisboa, APDR, 2002.

DA SILVA, A. C. O Processo de Ruptura Estrutural na Economia Regional Paranaense. Dissertação de Mestrado PGDRA/UNIOESTE, 2014.

DA SILVA, A. C.; DUARTE, P. H. E. As transformações produtivas e a desindustrialização brasileira. In: V Seminário Internacional de Integração e Desenvolvimento Regional - SIDER e II Seminário da Rede Iberoamericana de Estudos Sobre Desenvolvimento Territorial e Governança - SIDETEG, Toledo, PR. 2018.

DE ARAÚJO, T. B. Brasil nos anos noventa: opções estratégicas e dinâmica regional. Revista Brasileira de Estudos Urbanos e Regionais, n. 2, 1999. DOI: https://doi.org/10.22296/2317-1529.200on2p9

DE LIMA, J. F.; ALVES, L. R.; PIFFER, M.; PIACENTI, C. A. Análise regional das mesorregiões do Estado do Paraná no final do século XX. Revista Análise Econômica. Ano 24, n. 46. 2006.

DE LIMA, J. F.; EBERHARDT, P. H. C.; GENTILI, D. C.; HECK, A. L. Mudanças estruturais da ocupação de mão de obra na economia regional do Sudoeste paranaense no início do século XXI. Urbe Revista Brasileira de Gestão Urbana, v. 1, n. 2. 2009.

DINIZ, C. C. A Dinâmica regional recente da economia brasileira e suas perspectivas. Texto para discussão no 375. IPEA. Brasília: Ipea, 1995. 
DINIZ, C. C.; CROCCO, M. A. Reestruturação econômica e impacto regional: o novo mapa da indústria brasileira. Revista Nova Economia, Belo Horizonte, v. 6, n. 1, p. 77-103, 1996.

FILGUEIRAS, L. A Natureza do atual padrão de desenvolvimento brasileiro e o processo de desindustrialização. Relatório de Pesquisa. Centro Celso Furtado, Rio de Janeiro. 2012.

HADDAD, P. R.; ANDRADE, T. A.; Métodos de Análise Regional. In: HADDAD, P. R. Org. Economia Regional: Teorias e Métodos de Análise. Fortaleza, Banco do Nordeste do Brasil. ETENE, 1989.

INSTITUTO DE PESQUISA ECONÔMICA APLICADA - IPEA. Produtividade no Brasil nos anos 20oo2009. Comunicados do IPEA n. 133. 2012. Disponível em:

https://www.ipea.gov.br/portal/images/stories/PDFs/comunicado/120203_comunicadoipea133.pdf. Acesso em: 20 set. 2017.

LODDER, C. A. Padrões locacionais e desenvolvimento regional. Dissertação (Mestrado em Economia) Escola de Pós-Graduação em Economia (EPGE), do Instituto Brasileiro de Economia, da Fundação Getúlio Vargas. 1971.

MINISTÉRIO DO TRABALHO E EMPREGO - MTE. Dados e estatísticas da Relação Anual de Informações e Sociais (RAIS). RAIS Vínculos, 2017. Disponível em:

http://bi.mte.gov.br/bgcaged/rais.php. Acesso em: 15 set. 2017.

MONTEIRO NETO, A.; SILVA, R. de O. Desconcentração territorial e reestruturação regressiva da indústria no Brasil: padrões e ritmos. Texto para discussão 2402 / IPEA. Brasília: Rio de Janeiro: Ipea, 2018. ISSN 1415-4765.

PACHECO, C. A. Fragmentação da nação. Campinas: Instituto de Economia/ UNICAMP, 1998.

PIACENTI, C. A.; DE LIMA, J. F. (Orgs.) Análise regional: Metodologias e Indicadores. Curitiba, PR: Camões, 2012.

PIFFER, M. A dinâmica do Oeste paranaense: sua inserção na economia regional. Dissertação (Mestrado em Economia). Universidade Federal do Paraná - UFPR, 1997.

PIFFER, M. A. A teoria da base econômica e o desenvolvimento regional do Estado do Paraná no final do século XX. Tese (Doutorado em Desenvolvimento Regional). Universidade de Santa Cruz do Sul, 2009.

POCHMANN, M. O trabalho na crise econômica no Brasil: primeiros sinais. Estudos Avançados, v. 23, n. 66. 2009. Disponível em:

<http://www.revistas.usp.br/eav/article/view/10408/12117. Acesso em: 19 set. 2017. DOI:

https://doi.org/10.1590/So103-40142009000200004>

SAMPAIO, D. P. A desindustrialização em marcha no Brasil. Revista da Sociedade Brasileira de Economia Política, São Paulo, no 34, p. 33-55, 2013. Disponível em:

http://revista.sep.org.br/index.php/SEP/article/view/2/75. Acesso em 19 out. 2017.

SAMPAIO, D. P. Desindustrialização e desenvolvimento regional no Brasil (1985-2015). In: MONTEIRO NETO, A.; CASTRO, C. N. de; BRANDÃO, C. A. Desenvolvimento regional no Brasil: políticas, estratégias e perspectivas - Rio de Janeiro: Ipea, 2017. 
SANTOS, G. O.; DA SILVA, A. C. Especialização da Produção Agrícola na Mesorregião Oeste do Paraná 1995 a 2015. In: VIII SEMINÁRIO INTERNACIONAL SOBRE DESENVOLVIMENTO REGIONAL - SIDR. Santa Cruz do Sul, 2017.

Recebido em 30.10.18

Aprovado em 02.07.19 